\title{
Estimation of Stature from Upper Arm Length
}

\author{
Tripti Shakya ${ }^{1}$, Deepshikha Mishra ${ }^{2}$, Prabesh Pandey ${ }^{3}$ \\ ${ }^{1}$ Assistant Professor, Department of Anatomy, Patan Academy of Health Sciences (PAHS), Lalitpur, Nepal. \\ ${ }^{2,3}$ Lecturer, Department of Anatomy, Patan Academy of Health Sciences (PAHS), Lalitpur, Nepal
}

Corresponding Author: Tripti Shakya

\begin{abstract}
Introduction: Reconstruction of stature from long bones of the upper extremity is of great medicolegal relevance. Upper arm length (UAL) estimate stature with reasonable accuracy and is reliable factor for predicting stature. There is a strong relationship between stature and UAL and many sets of linear equation have been developed which are easiest and reliable methods for predicting relation between stature and body segments. These derived regression equations are population specific and cannot be applied in other populations. Studies on UAL for estimation of stature is lacking among Nepalese population. Hence, present study was conducted to investigate relationship between stature and UAL and to formulate regression formula for estimation of stature from UAL among Nepalese population.
\end{abstract}

Method: A cross-sectional study was conducted among 150 attendees of patient visiting male and female clinic in Patan hospital, Nepal. Among 150 participants 75 were male and 75 were female. In present study stature, right and left upper arm length was measured. Pearson's correlation coefficient (r) was calculated. Regression equation was formulated for reconstruction of stature from upper arm length of both sides as well as for both male and female separately.

Result: All the measured parameters i.e. stature, right upper arm length and left upper arm length were higher in male than female $(\mathrm{p}<0.001)$. Strong positive correlation was found between stature and UAL in both males and females thereby indicating that stature can be estimated from UAL.

Conclusion: UAL is a reliable body parameter for predicting stature. It can be of great help to anatomists, clinicians and anthropologists.

Keywords: Stature, upper arm length, correlation coefficient and regression equation

\section{INTRODUCTION}

Identification appears to be a critical consideration in the forensic medicine. The necessity of identifying dismembered human remain in cases of suicide, bomb blast, war, accident, earthquakes and crimes is a challenging task for medicolegal experts. ${ }^{1}$ Estimation of stature from anthropometric measurement of different part of skeletal elements has been area of critical interest to anatomist, anthropologists and forensic experts for century. ${ }^{2}$

Reconstruction of stature from long bones of the upper extremity is of great medico-legal relevance. There is a strong relationship between stature and long bones of the upper limb segments. ${ }^{3}$ For this purpose many sets of linear equation have been developed which are easiest and reliable methods for predicting relation between stature and body segments. Regression formulae derived from major long bones are generally considered to be more accurate than those utilizing other bones of hand and foot for estimating stature. $^{4}$

Upper arm length (UAL) estimate stature with reasonable accuracy and is reliable factor for predicting stature. ${ }^{5}$ Studies have shown that regression formulas derived reliably reconstructed stature with no statistically significant difference 
between measured and predicted mean stature. These derived regression equations are population based and cannot be applied in other populations. ${ }^{3}$

Therefore, Population specific studies are necessary for deriving population specific regression equation for reconstruction of stature. Several studies have been conducted to estimate stature from arm span, ulnar length, hand length and foot length but studies on upper arm length for estimation of stature is lacking among Nepalese population. Hence, present study was conducted to investigate relationship between stature and upper arm length and to formulate regression formula for estimation of stature from upper arm length among Nepalese population.

\section{MATERIALS AND METHODS}

This was a cross-sectional study conducted on 150 attendees of patient visiting male and female clinic in Patan hospital, Patan Academy of Health Sciences (PAHS), Lalitpur, Nepal. The duration of study was 1year from April 2020 to March 2021. Among 150 participants, 75 were male and 75 were female. Age of the participants ranged from 18-55 years. Those participants with skeletal deformity of upper limb or vertebral column and those not willing to participate in study were excluded from study. Measurements were taken from each participant using standard anthropometric technique. In present study stature (standing height), right upper arm length and left upper arm length were measured.

Stature (Standing Height): For measurement of stature participants were asked to stand erect in anatomical position with bare feet flat on the platform and head in Frankfurt's plane. The weight of the participant was evenly distributed on both feet with heels of the feet placed together and length from vertex to heel was measured using stadiometer and recorded in centimeters to the nearest one decimal place.

\section{Upper Arm Length}

For measurement of upper arm length participants were made to stand with the arm straight at the side of the body and bent at 90 degrees at the elbow joint. The distance from the acromion process to the olecranon process was measured using measuring tape and recorded in centimeters to the nearest one decimal place.

Ethical approval was obtained from Institutional Review Committee (IRC) of Patan Academy of Health Sciences (PAHS), Lalitpur, Nepal. Data collection was done after approval from IRC-PAHS. Informed written consent was taken from all the participants before data collection after explaining objective of the study.

\section{RESULT}

The mean age of participants was $31.76 \pm 10.384$ ranged from $18-55$ years. The mean \pm SD and range of participant stature, right upper arm length and left upper arm length is shown in table-1. All the measured parameters i.e. stature, right upper arm length (RUAL) and left upper arm length (LUAL) were higher in male participants compared to female which was statistically highly significant $(\mathrm{p}<0.001)$ as shown in table-2.

Pearson's correlation coefficient (r) was calculated and strong positive linear correlation was found between stature and upper arm length in both males and females and it was statistically highly significant $(p<0.001)$ as shown in table-3. Coefficient of determination $\left(\mathrm{R}^{2}\right)$ and standard error of estimate (SEE) was calculated and is shown in table-4.

Regression analysis was done and regression equation formulated for reconstruction of stature from length of upper arm of both sides for total study population as well as for both males and females separately as shown in table-5.

Using regression formula $\mathrm{Y}=\mathrm{A}+$ $\mathrm{BX}$, stature can be calculated from length of right and left arm length in male and female participants.

Where, 
$\mathrm{Y}=$ dependent variable (stature in $\mathrm{cm}$ ), $\mathrm{A}=$ constant, $\mathrm{B}=$ Regression coefficient of variable and $\mathrm{X}=$ independent variable (upper arm length in $\mathrm{cm}$ )

Table-1: Descriptive statistics of stature, right upper arm length and left upper arm length of total study population (n=150)

\begin{tabular}{|l|l|l|l|}
\hline Measured parameters & Mean \pm SD & Minimum & Maximum \\
\hline Stature & $161.171+9.45$ & 142.5 & 188.0 \\
\hline Right upper arm length & $39.5363+3.130$ & 34 & 50 \\
\hline Left upper arm length & $38.759+2.991$ & 34 & 49 \\
\hline
\end{tabular}

Table 2: Comparison of stature, right and left upper arm length among male and female participants

\begin{tabular}{|l|l|l|l|}
\hline Measured parameters & Male $(\mathbf{n}=75)$ mean \pm SD & Female $(\mathbf{n}=\mathbf{7 5})$ mean \pm SD & P value \\
\hline Stature & $168.047+7.094$ & $154.296+5.796$ & $<0.001$ \\
\hline Right upper arm length & $41.4667+2.993$ & $37.436+1.807$ & $<0.001$ \\
\hline Left upper arm length & $40.598+2.849$ & $36.920+1.735$ & $<0.001$ \\
\hline
\end{tabular}

Table-3: Correlation between stature and upper arm length of both sides in male and female participants

\begin{tabular}{|c|c|c|c|c|c|c|c|}
\hline \multirow[t]{4}{*}{ Stature } & \multirow{3}{*}{$\begin{array}{l}\text { Pearson's correlation } \\
\text { coefficient } \\
\text { (r) }\end{array}$} & \multicolumn{2}{|c|}{ Male $(n=75)$} & \multicolumn{2}{|c|}{ Female $(n=75)$} & \multicolumn{2}{|c|}{ Total $(n=150)$} \\
\hline & & RUAL & LUAL & RUAL & LUAL & RUAL & LUAL \\
\hline & & $0.893 * *$ & $0.895 * *$ & $0.779 * *$ & $0.739 * *$ & $0.911 * *$ & $0.900 * *$ \\
\hline & $\mathrm{P}$ value & $<0.001$ & $<0.001$ & $<0.001$ & $<0.001$ & $<0.001$ & $<0.001$ \\
\hline
\end{tabular}

$R U A L$-right upper arm length, LUAL-left upper arm length

Table-4 Coefficient of determination $\left(R^{2}\right)$ and standard error of estimate

\begin{tabular}{|l|l|l|l|l|l|l|}
\hline \multirow{3}{*}{ Stature } & \multicolumn{3}{|l|}{ Tale $(\mathbf{n}=\mathbf{7 5})$} & Female $(\mathbf{n}=\mathbf{7 5})$ & Total $(\mathbf{n}=\mathbf{1 5 0})$ \\
\cline { 2 - 7 } & & RUAL & LUAL & RUAL & LUAL \\
\cline { 2 - 7 } & $\mathrm{R}^{2}$ & 0.798 & 0.801 & 0.606 & 0.546 & 0.831 \\
\cline { 2 - 7 } & SEE & 3.207 & 3.184 & 3.662 & 3.932 & 3.907 \\
\hline
\end{tabular}

RUAL-right upper arm length, LUAL-left upper arm length

Table-5: Regression equation for estimating stature from upper arm length of both sides in male and female participants.

\begin{tabular}{|l|l|l|l|}
\hline \multirow{4}{*}{ Stature } & Participants & Right upper arm length & Left upper arm length \\
\cline { 2 - 4 } & Male & $2.117 \mathrm{x}+80.253$ & $2.228 \mathrm{x}+77.582$ \\
\cline { 2 - 4 } & female & $2.497 \mathrm{x}+60.812$ & $2.468 \mathrm{x}+63.164$ \\
\cline { 2 - 4 } & total & $2.051 \mathrm{x}+52.853$ & $0.707 \mathrm{X}+52.853$ \\
\hline
\end{tabular}

The coefficient of determination $\left(\mathrm{R}^{2}\right)$ was derived from correlation coefficient $(r)$. In case of male, right and left upper arm length determined the stature of individual by $79.80 \% \quad\left(\mathrm{R}^{2}\right)$ and $80.10 \% \quad\left(\mathrm{R}^{2}\right)$ respectively. Similarly, in female right and left upper arm length determined the stature of individual by $60.60 \%\left(\mathrm{R}^{2}\right)$ and $54.60 \%$ $\left(\mathrm{R}^{2}\right)$ respectively as shown in table- 4 . The estimated stature of male using either right upper arm length or left upper arm length may be equal. Likewise, in female estimated stature from right or left upper arm length may be equal.
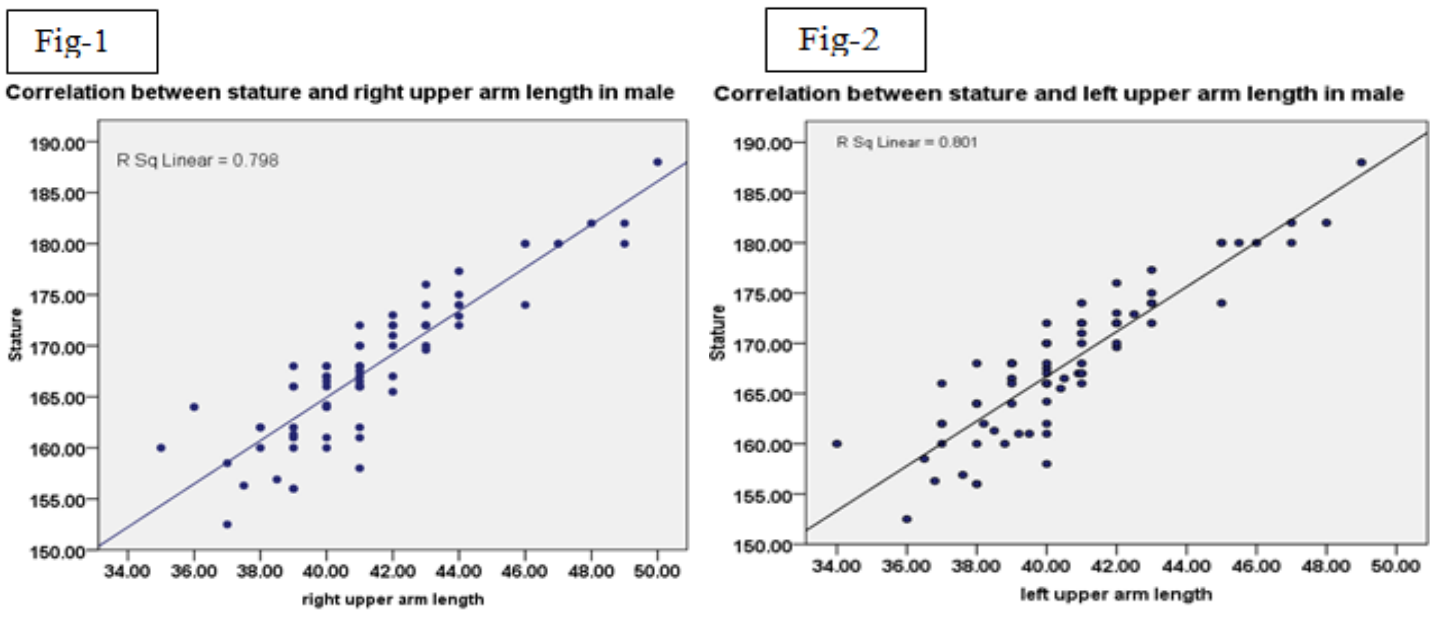

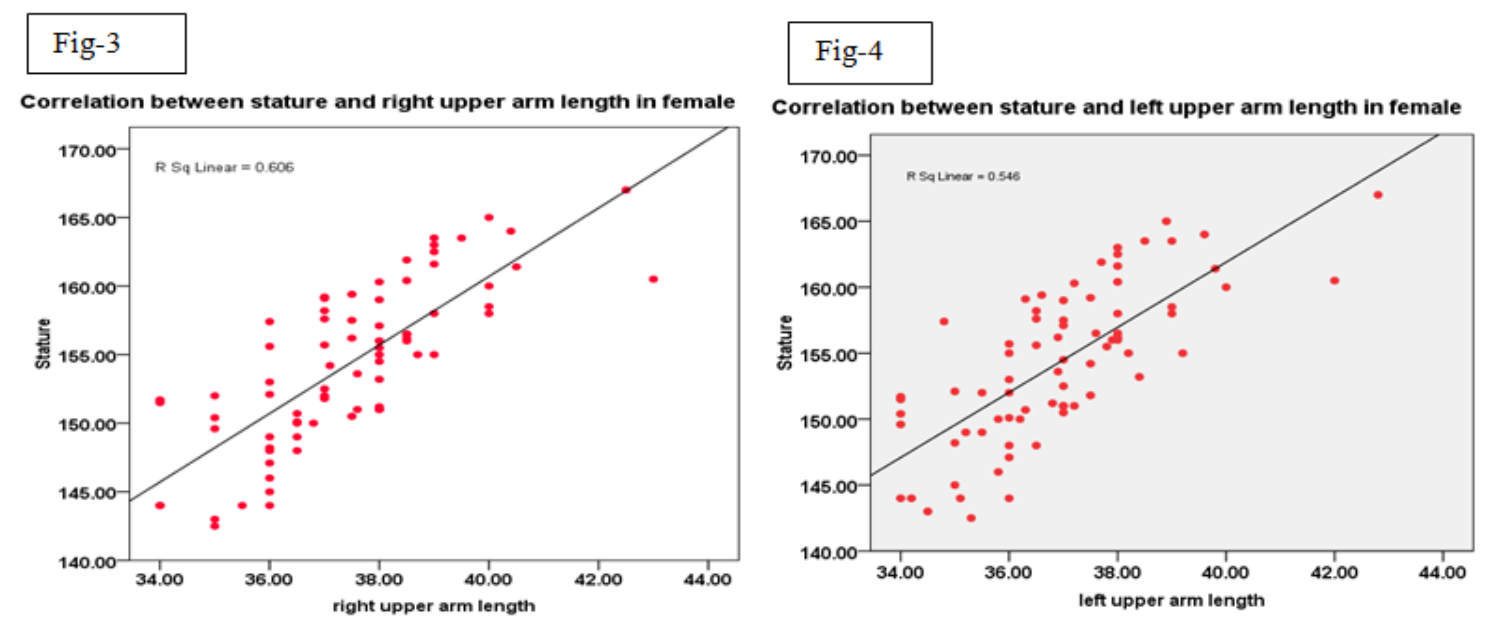

Fig-1-4: Scatter plot with best fit line with stature in $\mathrm{Y}$ axis and right upper arm length and left upper arm length in $\mathrm{X}$ axis showing relationship between stature and upper arm length of both sides in male and female.

Statistical analysis: The data from participants was collected and entered into Microsoft Excel sheet. Measurements obtained were analyzed using Statistical Package for Social Sciences (SPSS) software version 16. Descriptive data were presented as mean \pm standard deviation. Independent t-test was employed to compare the measurements of stature, right and left upper arm length between male and female participants. A $\mathrm{P}$ value of $<0.05$ was considered statistically significant.

Pearson's correlation coefficient (r) was analyzed to examine relationship between stature and upper arm length. Regression analysis was done to formulate Regression equations for estimation of stature from length of arm of both sides for total study population as well as for both males and females separately.

Coefficient of determination $\left(\mathrm{R}^{2}\right)$ was used to calculate the proportion of variance in stature in relation to length of upper arm. Standard errors of estimate (SEE) were also calculated.

\section{DISCUSSION}

Identification is the most important issue in forensic medicine. The long bones and their relation with stature can be useful in forensic identifications. Stature of individual is a variable parameter which is influenced by a variety of confounding factors like age, sex, ethnicity etc. Humerus being the longest and largest bone of upper limb, estimation of stature can be done from humeral length by formulating regression equation. In present study, upper arm length or percutaneous humerus length was evaluated among 18-55 years adult.

The present study showed that stature was statistically significantly higher among male as compare to female ( $\mathrm{p}<$ 0.001). Similar finding was also reported by Nandi et al, Arif et al. and Navid et al. ${ }^{3,5.6}$ This can be explained by genetic constitution of males as in male, age of puberty being 2 years later than females which give them additional time for growth. $^{7}$

In present study, right and left upper arm length was statistically significant higher in male than female $(\mathrm{p}<0.001)$. The obtained result of present study was in accordance with similar finding reported by Nandi et al., Arif et al., Navid et al., Uzun et al. and Lukpata et al. ${ }^{3.5 .6 .8 .9}$ It might be due to reason that taller people tend to have longer limbs than their shorter counterparts. This also suggests that the regression equation derived for one sex cannot be applied to estimate stature for other sex. So, the same regression equation can't be used in both sexes to estimate stature.

Pearson's correlation was used to predict the significant relationship between stature and upper arm length (UAL). In present study correlation coefficient (r) between stature and right upper arm length (RUAL) and left upper arm length (LUAL) 
in male was 0.893 and 0.895 respectively whereas, in female value of it was 0.779 and 0.739 respectively which revealed strong positive correlation between stature and UAL in both male and female. So, UAL can be used for estimation of stature in both sex and thus help to establish identity of an individual from unknown human remains. The highest correlation coefficient provides the highest reliability and accuracy in estimating stature of unknown male \& female. Similar positive correlation between stature and UAL was also documented by other studies conducted by Navid et al., Akhlaghi et al. and Airan et al. in different world populations. ${ }^{6,10.11}$ A study from Nigeria reported significantly higher correlation coefficient in male (RUAL-0.72 and LUAL 0.75) than female (RUAL-0.70 and LUAL 0.69) $\mathrm{P}<0.001$ which is similar to findings of present study. ${ }^{3}$ In another study conducted in India by Arif et al. and Mumtaz et al. documented value of $r$ to be significantly higher in female compared to males which contradicts with findings of present study showing higher significance in females. ${ }^{5,12}$

Regression analysis was done to know the strength of relation between UAL and stature. In present study regression equation was formulated for estimation of stature from UAL of both sides for total study population as well as for both males and females separately. Derived regression equation for male was stature (S) $=2.117 \times$ RUAL +80.253 and 2.228xLUAL+77.58 for right and left arm respectively. Whereas, for female $S$ $=2.497 x$ RUAL+60.812 and 2.468xLUAL +63.164 for right and left arm respectively.

Akhlaghi et al. formulated regression equation for male and female was $\mathrm{S}=\mathrm{UAl} \quad \mathrm{x} 1.886+107.334$ and $\mathrm{S}=\mathrm{UAlx} 1.911+98.099$ respectively. ${ }^{10}$ Navid et al. derived regression for Iranian population was $\mathrm{S}=91.641+2.509 \times \mathrm{UAL}$ and for Indian population by Airan et al. was $\mathrm{S}=2.37 \mathrm{x}$ RUAL +92.95 and 2.39xLUAL+92.76 for right and left arm respectively in case of male whereas, in female $\mathrm{S}=2.44 \mathrm{xRUAL}+82.88$ and $2.36 \mathrm{x}$ LUAL+85.44 for right and left arm respectively. ${ }^{6,11}$ In another study conducted by Shah $\mathrm{T}$ et al. reported it to be $\mathrm{S}=47.258+1.476$ (UAL) and 97.205+0.716 (UAL) for male and female respectively among Muslims of Gujarat. ${ }^{13}$ Regression equation derived for different population is different which might be due to genetic, nutrition, geographical location, physical activity and various races which affect the anthropometric data. ${ }^{10}$ So, population specific regression equation must be used for reconstruction of stature from upper arm length.

Standard error of estimate (SEE) is a good parameter to evaluate accuracy of the simple linear regression equations and coefficient of determination $\left(\mathrm{R}^{2}\right)$ is a statistical measure of how well the regression predictions approximate the real data points. In present study value of SEE in male was (RUAL-3.207 and LUAL-3.184) and in female was (RUAL-3.662 and LUAL-3.932). Likewise, value of $\mathrm{R}^{2}$ in male was (RUAL-0.798 and LUAL-0.801) and in female was (RUAL-0.606 and LUAL-0.546). Such findings further strengthen the previous claims that long bones are reliable in stature estimation with lower chances of errors due to low SEE and high coefficients of determination.

The male cases recorded SEE and $\mathrm{R}^{2}$ values of 4.520 and 0.398 respectively, while in female recorded SEE and $\mathrm{R}^{2}$ values was 4.32 and 0.435 , respectively Their results showed higher SEE in males than females and lower $\mathrm{R}^{2}$ values in males than females, which is similar to the results of the present study. This connotes that the regression models derived for stature reconstruction from this study could be more reliable than the report of Navid et al.

A study from India reported higher SEE and lower value of $\mathrm{R}^{2}$ in male than female which is contrary to the finding of present study. ${ }^{11}$ Derived regression equation in Pakistan was more accurate than that of present study as their study reported low SEE and high value of $\mathrm{R}^{2}$ than our study. 
On the other hand, when findings of present study was compared with previous studies conducted by Navid et al., Airan et al., and Shah $T$ et al. value of SEE was lower and value of $\mathrm{R}^{2}$ was higher in present study which signifies that the derived regression equation in present study is more accurate predictors for stature estimation compared to those previous studies. ${ }^{6,11,13}$

\section{CONCLUSION}

Strong and significant correlation exist between stature and upper arm length so from present study it can be concluded that upper arm length is a reliable body parameter for predicting stature. If either of these measurements is known then other can be calculated fairly accurately. These are of considerable significance for forensic anthropometric and archaeological investigators in reconstruction of stature of an individual which can prove to be a useful tool for forensic scientists in medicolegal investigation when only fragmentary remains of the body are available. It can also be of great help to anatomists, clinicians and anthropologists. The derived regression equations are population specific and cannot be applied in other populations. Therefore, Population specific studies are necessary for deriving population specific regression equation for reconstruction of stature. The derived equations can be used to assess the nutritional status of hospitalized bedridden patients as well in people with skeletal deformity.

\section{ACKNOWLEDGEMENTS}

We would like to thank Patan Academy of Health Sciences, Nepal for providing research environment. We are grateful to all the participants who participated in this study. We also would like to thank Mr. Asta Maharjan for assisting in data collection.

Funding: No funding sources

Conflict of Interest: None declared
Ethical Approval: Approval was obtained from institutional review committee of PAHS.

\section{REFERENCES}

1. Choudhary S, Singh H, Gupta N. Estimation of stature from combined length of forearm and hand in Jammu region of India. International Journal of Basic and Applied Sciences. 2013;3(1):8-10.

2. Manouvrier L. Stature estimation from the measurements of the hand and the second metacarpal bone. Rev Ec Anthropol 1892;2: 227-3.

3. Nandi ME, Olabiyi OA, Ibeabuchi NM , Okubike EA, IheazaEC.Stature Reconstruction from Percutaneous Anthropometry of Long Bones of Upper Extremity of Nigerians in the University of Lagos. Arab Journal of Forensic Sciences \& Forensic Medicine 2018;1(7):869-80.

4. Singh S, Nair SK, Anjankar V, Bankwar V, Satpathy DK. Regression equation for estimation of femur length in Central Indians from Inter-trochanteric crest. J Indian Acad Forensic Med. 2013;35(3): 223-26.

5. Arif M, Rasool SH, Chaudhary MK, Shakeel Z. Estimation of stature; upper arm length - a reliable predictor of stature. Professional Med J 2018; 25(11):16961700.

6. Navid S, Mokhtari T, Alizamir T, Arabkheradmand A, Hassanzadeh G. Determination of Stature from Upper Arm Length in Medical Students Anatomical Sciences. 2014;11(3):135-40.

7. Cutler Jr GB. The role of estrogen in bone growth and maturation during childhood and adolescence. J Steroid Biochem Mol Biol. 1997;n61(3e6):141e4.

8. ozlem Uzun ,Gulay Yegİnoglu, Canan Ertemoglu oksuz, sahi Nur Kalkısım, Nihat Burak Zihni. Estimation of Stature from Upper Extremity Anthropometric Measurements. Journal of Clinical and Diagnostic Research. 2019;3(1): AC09AC15

9. Lukpata PU, Esomonu UG, Ewununu EO, Mba CE. Correlation between height and selected anthropometric parameters of the upper limbs of the Efiks people in Cross River state, Nigeria. J Pharm Biomed Sci. 2016;06(01): 46-49 
10. Akhlaghi M, Hajibeygi $M$, Zamani N, Moradi B. Estimation of stature from upper limb anthropometry in Iranian population. Journal of Forensic and Legal Medicine. 2012; 19(5):280-4.

11. Airan N, Dwivedi AK, Das AR and Mishra SK. Estimation of stature from length of arm in adult population of Garhwal region of Uttarakhand, India. International Journal of Biomedical Research 2016; 7(12): 84246

12. Mumtaz SH, Sharma BR. Estimation of Stature from Right Upper Limb
Measurements. Santosh University Journal of Health Sciences. 2015;1(2):53-56

13. Shah T, Patel MN, Nath S and Menon SK. A Model for Construction of Height and Sex from Shoulder Width, Arm Length and Foot Length by Regression Method. Journal of Forensic Science \& Criminology. 2015; $3(1): 1-7$

How to cite this article: Shakya T, Mishra D, Pandey P. Estimation of stature from upper arm length. Int J Health Sci Res. 2021; 11(5): 23-29. DOI: https://doi.org/10.52403/ijhsr.20210503 